\section{Successful treatment for hypopharyngeal cancer in a patient with superficial esophageal cancer by endoscopic submucosal dissection}

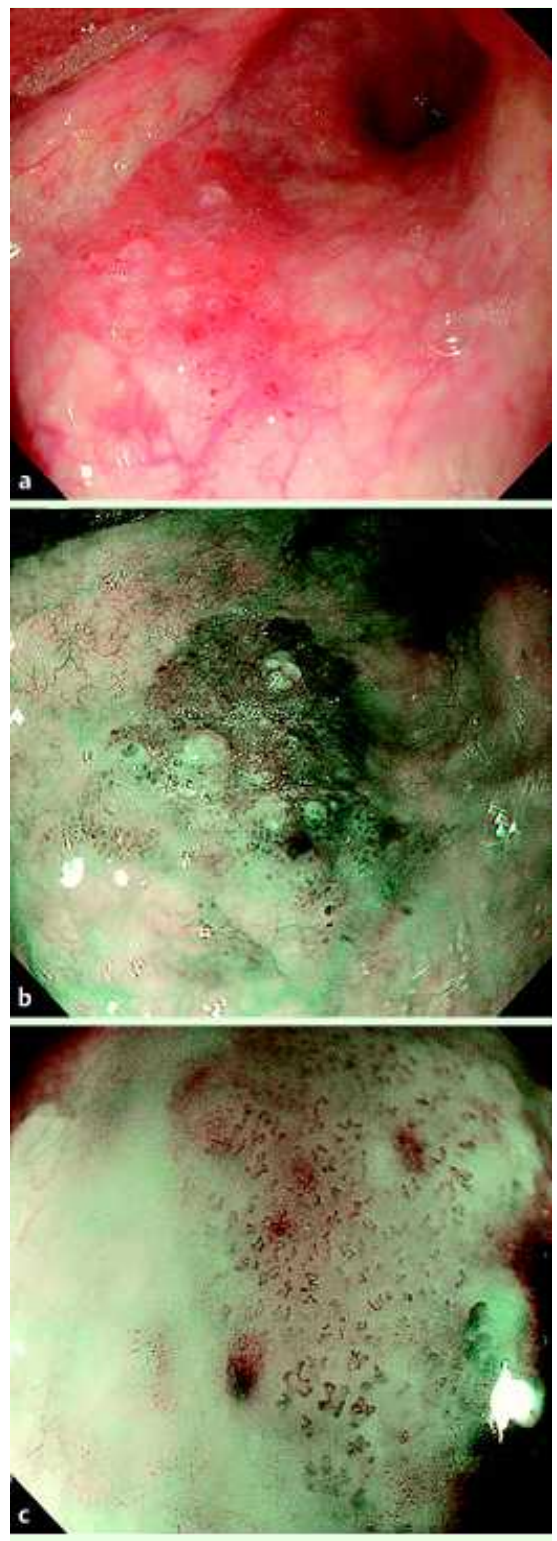

Fig. 1 Upper endoscopic findings for the hypopharynx. a A slightly elevated lesion with fine granular changes and absence of continuity with blood vessels, approximately $1.6 \mathrm{~cm}$ in diameter, was detected synchronously in the posterior wall of the hypopharynx. $\mathbf{b}$ With the narrow band imaging (NBI) system, this lesion displayed a clearly demarcated brownish area. c Using the NBI system with a magnifying endoscope, the intrapapillary capillary loop took on irregular shapes including dilation, tortuosity, caliber change, and meandering. These observations suggested that the lesion would have malignant potential.
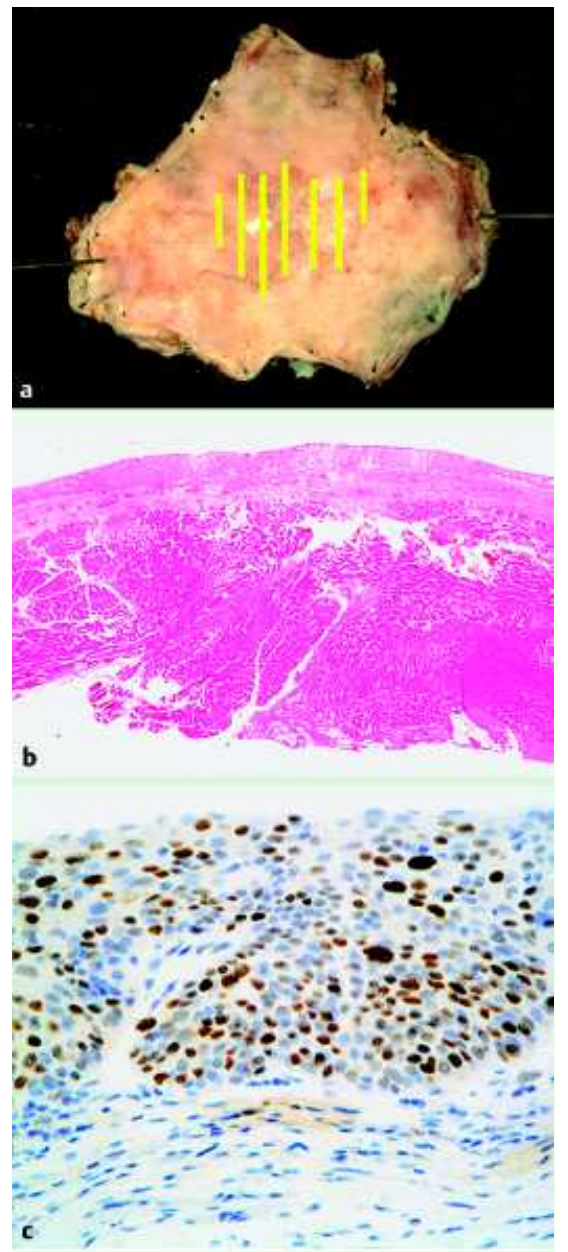

Fig. 2 Macroscopic and pathologic findings. a The resected specimen measured $3.5 \times$ $3.0 \mathrm{~cm}$ and macroscopically, resected margins were almost optimal circumferentially $(\times 1)$. The extent of cancer spread was schematically drawn using yellow color lines, and measured $1.7 \times 1.3 \mathrm{~cm}$. b Histologic findings revealed noninvasive, moderately differentiated squamous cell carcinoma limited to the lamina propria mucosae without vessel or lymphatic infiltration. In addition, both horizontal and vertical margins were sufficient $(\times 20)$. c lmmunohistochemistry revealed $\mathrm{p} 53$-positive cells were randomly widespread in the outer basal cell layer $(\times 200)$.

A 68-year-old man with a history of laryngectomy for laryngeal cancer 3 years earlier was diagnosed with superficial esophageal squamous cell carcinoma (ESCC). In addition, a slightly elevated lesion $(1.6 \mathrm{~cm})$ was detected synchronously in the posterior wall of the hypopharynx (๑ Fig. 1 a). Using a narrow-band imaging (NBI) system with magnifying endoscopy (GIF TYPE H260Z; Olympus), this lesion displayed a clearly demarcated brownish area ( $\bullet$ Fig. 1 b) and the intrapapillary capillary loop (IPCL), which was advocated by Inoue et al. [1], took on irregular shapes ( $\bullet$ Fig. 1 c). For treatment of the hypopharyngeal lesion, endoscopic submucosal dissection (ESD) was performed under general anesthesia followed by subtotal esophagectomy. A mucosal incision was made with the flex knife and the subepithelial tissue was cut with a hook knife. Macroscopic examination of the resected specimen $(3.5 \times$ $3.0 \mathrm{~cm}$ ) revealed cancer spread over an area of $1.7 \times 1.3 \mathrm{~cm}$ ( $\odot$ Fig. 2 a). Histologically, noninvasive squamous cell carcinoma was limited to the epithelial layers without either vessels or lymphatic infiltration, and both horizontal and vertical margins were sufficient ( $\bullet$ Fig. $\mathbf{2}$ b). Immunohistochemistry revealed that p53positive cells were widespread in the outer basal cell layer ( $\bullet$ Fig. 2 c). This observation led to a diagnosis of squamous cell carcinoma of the hypopharynx, not a dysplastic lesion or regenerative changes. One of the hallmarks of ESCC is synchronous or metachronous tumors arising in the head and neck [2]. An NBI system with magnifying endoscopy is useful for acquiring valuable information about small lesions of the hypopharynx [3], and ESD is a more favorable method than endoscopic mucosal resection for earlystage hypopharyngeal cancer located in anatomically complex areas [4]. In conclusion, an NBI system with magnifying endoscopy has increased the chance of early detection of hypopharyngeal cancer, and ESD would be the optimal method of treatment at least for early-stage hypopharyngeal cancer.

\section{Endoscopy_UCTN_Code_TTT_1AO_2AG}

Y. Fujita ${ }^{1}$, M. Hiramatsu ${ }^{1}$, M. Kawai ${ }^{1}$, K. Tashiro ${ }^{1}$, E. Umegaki², S. Tokioka², Y. Egashira ${ }^{3}$, K. Higuchi ${ }^{2}$, N. Tanigawa Department of General and Gastroenterological Surgery, Osaka Medical College, Osaka, Japan

Second Department of Internal Medicine, Osaka Medical College, Osaka, Japan

First Department of Pathology, Osaka Medical College, Osaka, Japan 
References

1 Kumagai Y, Inoue H, Nagai K et al. Magnifying endoscopy, stereoscopic microscopy, and the microvascular architecture of superficial esophageal carcinoma. Endoscopy 2002; 34: 369-375

2 Motoyama S, Saito R, Kitamura M, Ogawa J. Outcomes of active operation during intensive followup for second primary malignancy after esophagectomy for thoracic squamous cell esophageal carcinoma. J Am Coll Surg 2003; 197: $914-920$

3 Muto M, Nakane M, Katada $C$ et al. Squamous cell carcinoma in situ at oropharyngeal and hypopharyngeal mucosal sites. Cancer 2004; 101: 1375-1381

4 Shimizu Y, Yamamoto J, Kato $M$ et al. Endoscopic submucosal dissection for treatment of early stage hypopharyngeal carcinoma. Gastrointest Endosc 2006; 64: 255 - 259; discussion 260-252
Bibliography

DOI $10.1055 / \mathrm{s}-2007-995570$

Endoscopy 2008; 40: E189-E190

(c) Georg Thieme Verlag KG Stuttgart · New York . ISSN 0013-726X
Corresponding author

\section{N. Tanigawa, MD}

Department of General and Gastroenterological Surgery

Osaka Medical College

2-7 Daigaku-machi

Takatsuki-city

Osaka 569-8686

Japan

Fax: +81-72-685-2057

sur001@poh.osaka-med.ac.jp 